\title{
Componentes de produção, produtividade e atributos tecnológicos de cultivares de feijoeiro do grupo comercial carioca
}

Filippo Perondi de Santis, Almir Salvador Neto, Adailza Guilherme Cavalcante, Vinicius Augusto Filla, Fabio Luiz Checchio Mingotte, Leandro Borges Lemos

Universidade Estadual Paulista - UNESP, Câmpus de Jaboticabal, SP. E-mail: filla.vinicius@gmail.com

\section{Resumo}

As cultivares de feijoeiro, além da adaptação ao local de cultivo, devem apresentar alto potencial produtivo e atender as exigências dos consumidores quanto aos atributos qualitativos. O objetivo com este trabalho foi avaliar os componentes de produção, produtividade e atributos qualitativos de cultivares de feijoeiro do grupo comercial carioca no período de outono-inverno, visando obter informações referentes à capacidade produtiva e à qualidade dos grãos. O delineamento experimental utilizado foi o de blocos casualizados, com 13 tratamentos e quatro repetições. Os tratamentos foram constituídos pelas cultivares de feijoeiro: Pérola, BRS Estilo, BRSMG Madrepérola, BRS Notável, IAC Alvorada, IAC Imperador, IAC Milênio, IPR 139 (Juriti Claro), IPR Andorinha, TAA Bola Cheia, TAA Dama, TAA Gol e ANfc 9. Todas as cultivares de feijoeiro destacaram-se quanto a produtividade de grãos, com valor médio de $3.400 \mathrm{~kg} \mathrm{ha}^{-1}$, superando as produtividades médias de todos os estados brasileiros. As cultivares, BRS Estilo, IAC Alvorada, IPR Andorinha e TAA Gol apresentaram boa qualidade tecnológica dos grãos, destacando-se o elevado rendimento de peneiras e os menores tempos de cozimento. As cultivares BRS Estilo e TAA Dama apresentaram tempo de hidratação ideal, enquanto as cultivares Pérola, BRSMG Madrepérola e IPR 139 demandam maior tempo para o preparo.

Palavras-chave: genótipos; Phaseolus vulgaris L.; qualidade de sementes.

Yield components and technological attributes of common bean cultivars from carioca commercial group

\begin{abstract}
Bean cultivars, in addition to adaptation to the growing site, must present high productive potential and meet the consumers' requirements regarding the qualitative attributes. The objective of this work was to evaluate the yield components, yield and qualitative attributes of common-bean cultivars of carioca commercial group in the autumn-winter period, aiming to obtain information regarding the productive capacity and grain quality. The experimental design was a randomized block design with 13 treatments and four replications. The treatments consisted of bean cultivars: Pérola, BRS Estilo, BRSMG Madrepérola, BRS Notável, IAC Alvorada, IAC Imperador, IAC Milênio, IPR 139 (Juriti Claro), IPR Andorinha, TAA Bola Cheia, TAA Dama, TAA Gol e ANfC 9. All common bean cultivars stood out for grain yield, with an average value of $3,400 \mathrm{~kg} \mathrm{ha}^{-1}$, surpassing the average yields of all Brazilian states. The cultivars BRS Estilo, IAC Alvorada, IPR Andorinha and TAA Gol presented good technological quality of the grains, highlighting the high yield of sieves and shorter cooking times. The cultivars BRS Estilo and TAA Dama presented ideal hydration time, while the cultivars Pérola, BRSMG Madrepérola and IPR 139 require more time to prepare.
\end{abstract}

Keywords: genotypes; Phaseolus vulgaris L.; seed quality.

\section{Introdução}

O feijão (Phaseolus vulgaris L.) representa $50 \%$ do volume de grãos consumidos no mundo
(TALUKDER et al., 2010). Seus grãos são utilizados para suprir as necessidades energéticas da dieta dos brasileiros (SILVA et al., 2014). Seu consumo 
é destaque em países em desenvolvimento, em regiões tropicais e subtropicais, especialmente por suas propriedades alimentares (JESUS et al., 2013). No Brasil são cultivados diferentes tipos de grãos de feijoeiro, dos quais o 'carioca' é o mais amplamente consumido e comercializado, representando aproximadamente $70 \%$ do total de grãos (MELO et al., 2012).

A produção brasileira de feijão é da ordem de 3,12 milhões de toneladas, em uma área plantada de 3,17 milhões de hectares, resultando em uma produtividade média de 982 $\mathrm{kg} \mathrm{ha}^{-1}$. Dentro do período de inverno ou 3a safra (feijão de inverno), o Brasil produziu $619 \mathrm{mil}$ toneladas na safra 2017/2018 (CONAB, 2019), apresentando elevadas produtividades em função do nível tecnológico adotado, empregando-se cultivares com elevado potencial produtivo, uso de sistemas de irrigação, maior fornecimento de fertilizantes (ALMEIDA; MELO, 2016; PACHECO et al., 2012).

De acordo com Lemos et al. (2015), em razão do produto feijão ser um alimento destinado aos seres humanos, os principais critérios utilizados na escolha correta da cultivar está embasado nos atributos produtivos, tais como população final de plantas, número de vagens por planta, número de grãos por vagem, massa de 100 grãos e produtividade de grãos. Os atributos qualitativos desejados pelos consumidores são menor tempo para o cozimento, alta capacidade de hidratação, apresentando não só quantidade, mas também, qualidade proteica (PERINA et al., 2010; MINGOTTE et al., 2013).

Segundo o Registro Nacional de Cultivares (RNC), estão registradas cerca de 350 cultivares de feijoeiro (BRASIL, 2019), as quais apresentam diferentes interações genótipo-ambiente. Portanto, faz-se necessário um intenso estudo por cultivares produtivas e adaptadas às mais diversas regiões do país (FARINELLI; LEMOS, 2010a), visando verificar a adaptação das cultivares a um determinado ambiente de cultivo, bem como suas características produtivas e qualitativas para atender os produtores $\mathrm{e}$ consumidores. Diante disso, o objetivou-se avaliar os componentes de produção, produtividade e atributos qualitativos de cultivares de feijoeiro do grupo comercial carioca no período de outono-inverno.

\section{Material e Métodos}

O experimento foi conduzido na Fazenda de Ensino, Pesquisa e Extensão (FEPE) da Faculdade de Ciências Agrárias e Veterinárias da UNESP, Campus de Jaboticabal-SP, situada na latitude $21^{\circ} 14^{\prime} 33^{\prime \prime} \mathrm{S}$ e longitude de $48^{\circ} 17^{\prime} 10^{\prime \prime} \mathrm{W}$, com uma altitude média de $565 \mathrm{~m}$ acima do nível do mar. O clima segundo a classificação de Köppen é do tipo Aw, tropical úmido com estação chuvosa no verão e seca no inverno. As condições climáticas durante a condução do experimento, como precipitação pluvial e as temperaturas máxima e mínima são apresentadas na Figura 1.

Figura 1. Temperatura máxima (Tmáx), mínima (Tmin) e precipitação pluvial (Precp) registradas durante o decorrer do ciclo das cultivares de feijoeiro do grupo comercial carioca, na safra de inverno.

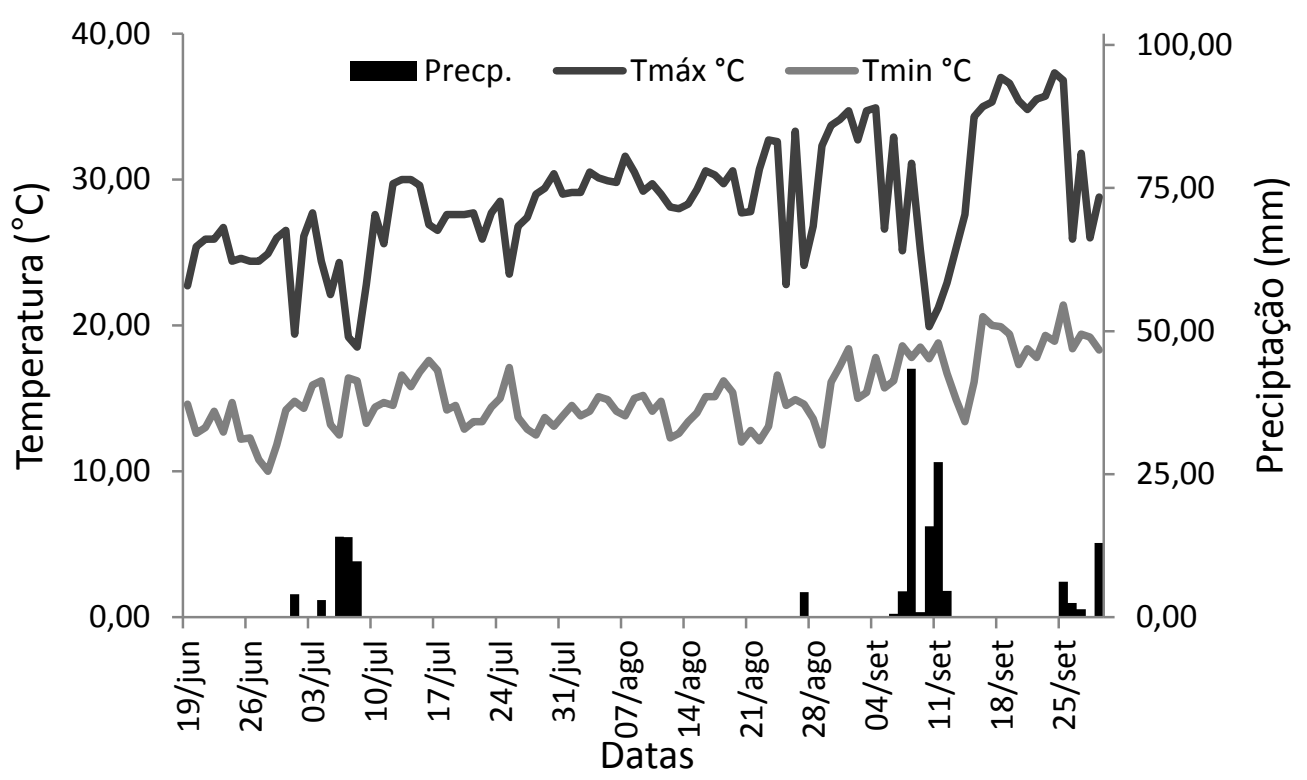


O delineamento experimental utilizado foi o de blocos casualizados, com 13 tratamentos e 4 repetições. Os tratamentos foram constituídos pelas seguintes cultivares de feijoeiro do grupo comercial carioca: Pérola, BRS Estilo, BRSMG Madrepérola, BRS Notável, IAC Alvorada, IAC Imperador, IAC Milênio, IPR 139 (Juriti Claro), IPR Andorinha, TAA Bola Cheia, TAA Dama, TAA Gol e ANfc 9. Cada parcela experimental foi constituída por quatro linhas de $5 \mathrm{~m}$ de comprimento e espaçadas em $0,45 \mathrm{~m}$. As duas linhas centrais de cada parcela foram consideradas como área útil.

$\mathrm{Na}$ área experimental, a cultura anterior foi milho e o preparo do solo foi realizado por meio do uso de uma aração e duas gradagens. A semeadura das cultivares foi realizada manualmente no dia 19 de junho de 2015, sendo caracterizado feijão da safra de inverno ou 3 a safra (PIZZAN et al., 1994). Foram distribuídas 12 sementes $\mathrm{m}^{-1}$ no sulco de semeadura, resultando, em média, 240 mil plantas ha ${ }^{-1}$ no momento da colheita.

O solo da área experimental foi caracterizado como Latossolo Vermelho eutroférrico, de acordo com a classificação da Embrapa (2018). Previamente à instalação do experimento, foi realizada a amostragem de solo na camada de $0-20 \mathrm{~cm}$ com o intuito de avaliar as características de fertilidade do solo, obtendo-se os seguintes valores: $\mathrm{pH}\left(\mathrm{CaCl}_{2}\right): 5,6 ; \mathrm{M} .0 .: 24 \mathrm{~g}$ $\mathrm{dm}^{-3}$; P (resina): $41 \mathrm{mg} \mathrm{dm}^{-3} ; \mathrm{K}: 5,7 \mathrm{mmol}_{\mathrm{c}} \mathrm{dm}^{-3}$; Ca: $30 \mathrm{mmol}_{\mathrm{c}} \mathrm{dm}^{-3} ; \mathrm{Mg}: 14 \mathrm{mmol}_{\mathrm{c}} \mathrm{dm}^{-3} ; \mathrm{H}+\mathrm{Al}: 28$ $\mathrm{mmol}_{\mathrm{c}} \mathrm{dm}^{-3}$; CTC: $78 \mathrm{mmol}_{\mathrm{c}} \mathrm{dm}^{-3}$; SB: $50 \mathrm{~mm}_{\mathrm{c}} \mathrm{dm}^{-}$ 3. V: $64 \%$.

Conforme a análise química do solo e recomendação do Boletim Técnico 100 (AMBROSANO et al., 1997) foi realizado o cálculo de adubação utilizando-se $250 \mathrm{~kg} \mathrm{ha}^{-1}$ do formulado 4-20-20, fornecendo assim $10 \mathrm{~kg} \mathrm{ha}^{-1}$ de $\mathrm{N}, 50 \mathrm{~kg} \mathrm{ha}^{-1}$ de $\mathrm{P}_{2} \mathrm{O}_{5}$ e $50 \mathrm{~kg} \mathrm{ha}{ }^{-1}$ de $\mathrm{K}_{2} \mathrm{O}$. A adubação de cobertura foi realizada fornecendose $90 \mathrm{~kg} \mathrm{ha}^{-1}$ de $\mathrm{N}$, via ureia no estádio fenológico de $V_{4}$, com o terceiro trifólio desenvolvido (AMBROSANO et al., 1997). Logo após a adubação de cobertura foi realizada irrigação com lâmina bruta de $10 \mathrm{~mm}$, com o intuito de incorporação da ureia. Foi realizado o fornecimento de água por meio de sistema de irrigação convencional por aspersão, com aplicação de lâmina total de $360 \mathrm{~mm}$, seguindo as recomendações de Lopes et al. (2004), somando- se à precipitação pluvial de $155 \mathrm{~mm}$, totalizando 515 mm de lâmina d'água.

Durante a condução do experimento, por ocasião da maturação fisiológica $\left(R_{9}\right)$ de cada cultivar de feijoeiro, foram coletadas 10 plantas na linha de cultivo na área útil de cada parcela experimental. Posteriormente, foram avaliados os componentes de produção: o número de vagens por planta, número de grãos por vagem e massa de 100 grãos. Para a obtenção da produtividade de grãos $\left(\mathrm{kg} \mathrm{ha}^{-1}\right)$, foi realizado o arranquio das plantas da área útil de cada parcela experimental e posteriormente, secagem a pleno sol. Depois foi feita a trilhagem de forma mecanizada e estimada a produção de grãos para grau de umidade de $13 \%$ (base úmida).

Os atributos tecnológicos avaliados foram: rendimento de peneira (\%), sendo os grãos classificados em tamanho pela passagem em conjunto de peneiras de crivos oblongos $11 / 64^{\prime \prime} \times 3 / 4(4,37 \times 19,05 \mathrm{~mm}), 12 / 64 " \times 3 / 4$ $(4,76 \times 19,05 \mathrm{~mm}), 13 / 64^{\prime \prime} \times 3 / 4(5,16 \times 19,05$ $\mathrm{mm}), 14 / 64^{\prime \prime} \times 3 / 4(5,56 \times 19,05 \mathrm{~mm})$ e $15 / 64 " \times$ $3 / 4(5,96 \times 19,05 \mathrm{~mm})$ em agitação por um minuto, adaptando-se a metodologia de Carbonell et al. (2010). O percentual de grãos foi calculado por meio da relação entre o peso dos grãos retidos em cada peneira e o peso da amostra total de cada repetição. $O$ rendimento na peneira igual ou maior que 12 foi composta pelos grãos retidos nas peneiras com crivos oblongos de 12 a 15.

$\mathrm{O}$ teor de proteína bruta nos grãos (\%) foi determinado por meio do cálculo: $\mathrm{PB}=\mathrm{N}$ total $x 6,25$ onde, $\mathrm{PB}=$ teor de proteína bruta nos grãos (\%) e $\mathrm{N}$ total = teor de nitrogênio nos grãos, obtido de acordo com a metodologia proposta por Sarruge e Haag (1974). A avaliação do tempo de cozimento (minutos) foi realizada com o auxílio do cozedor de Mattson modificado, o qual possui 25 estiletes verticais terminados em ponta de $1 / 16 "$ ". A ponta fica apoiada no grão de feijão durante o cozimento e, quando o grão se encontra cozido, a ponta penetra-o deslocando o estilete. O tempo final para cozimento da amostra foi obtido quando $50 \%+1$, ou seja, com o deslocamento de 14 estiletes. Para essa determinação os grãos ficaram em hidratação em água destilada durante um período de 12 horas. Durante a condução do teste foi verificada a temperatura da água que foi de $96^{\circ} \mathrm{C}$.

A capacidade de hidratação foi determinada por meio da utilização de uma 
proveta graduada com capacidade de $500 \mathrm{~mL}$ e precisão de $5 \mathrm{~mL}$ e béqueres com capacidade de $250 \mathrm{~mL}$. Em cada béquer foi colocada uma amostra, constituída de aproximadamente 50 gramas de grãos previamente escolhidos, adicionando-se $200 \mathrm{~mL}$ de água destilada. Durante o tempo de 16 horas foram feitas avaliações do volume de água não absorvido pelos grãos, vertendo-a do béquer para a proveta, em intervalos de uma hora. Ao final do tempo previsto para a hidratação a água foi totalmente drenada e os grãos pesados. A relação de hidratação foi determinada como sendo a razão entre a massa após a hidratação e a massa inicial dos grãos. Durante a condução do teste foi verificada constantemente a temperatura da água, que foi de $25^{\circ} \mathrm{C}$. Também foi realizado o estudo de regressão polinomial entre o tempo e a capacidade de hidratação, visando determinar o tempo necessário para que ocorresse a máxima hidratação dos grãos de feijão.

Os dados coletados foram submetidos à análise de variância utilizando-se o teste $F$, comparando-se as médias pelo teste de agrupamento de Scott e Knott (1974). Os cálculos estatísticos foram realizados utilizando o programa computacional SISVAR versão 5.6 (FERREIRA, 2011).

\section{Resultados e Discussão}

Os resultados obtidos referentes aos componentes de produção, tais como número de vagens por planta, número de grãos por vagens e massa de 100 grãos apresentaram diferenças significativas entre as cultivares de feijoeiro. No entanto, verificou-se que não houve diferença estatística entre as cultivares de feijoeiro para a produtividade de grãos (Tabela 1).

Observou-se diferença significativa para o número de vagens por planta, destacando-se as cultivares BRS Notável, IAC Alvorada, IAC Imperador, IAC Milênio, IPR 139 e IPR Andorinha, com valores médios variando de 11 a 13 vagens por planta (Tabela 1). Martins et al. (2009) obtiveram resultados semelhantes avaliando a cultivar de feijoeiro BRSMG Majestoso, obtendose média de 12 vagens por planta. O maior número de vagens não implica necessariamente em maior produtividade, pois o desempenho produtivo depende também dos demais componentes de produção.

Tabela 1. Número de vagens por planta, número de grãos por vagem, massa de 100 grãos e produtividade de grãos de cultivares de feijoeiro do grupo comercial carioca, no período de inverno ${ }^{(1)}$.

\begin{tabular}{|c|c|c|c|c|}
\hline \multirow[t]{2}{*}{ Cultivares } & $\begin{array}{l}\text { Vagens por } \\
\text { planta }\end{array}$ & $\begin{array}{l}\text { Grãos por } \\
\text { vagem }\end{array}$ & \multirow{2}{*}{$\begin{array}{c}\text { Massa de } 100 \\
\text { grãos } \\
\text {-----(g)----- }\end{array}$} & \multirow[t]{2}{*}{$\begin{array}{c}\text { Produtividade de } \\
\text { grãos } \\
---\left(\mathrm{kg} \mathrm{ha}^{-1}\right)---\end{array}$} \\
\hline & \multicolumn{2}{|c|}{ - } & & \\
\hline Pérola & $8 \mathrm{~b}$ & $4,7 a$ & 30,3 a & 3.383 \\
\hline BRS Estilo & $10 \mathrm{~b}$ & $4,3 b$ & $28,8 \mathrm{~b}$ & 3.500 \\
\hline BRSMG Madrepérola & $9 \mathrm{~b}$ & $4,7 \mathrm{a}$ & $27,5 b$ & 3.900 \\
\hline BRS Notável & $13 a$ & $4,4 \mathrm{a}$ & $27,0 \mathrm{~b}$ & 3.415 \\
\hline IAC Alvorada & $13 a$ & $4,5 \mathrm{a}$ & 29,3 a & 3.752 \\
\hline IAC Imperador & $12 \mathrm{a}$ & $4,1 \mathrm{~b}$ & $25,9 \mathrm{~b}$ & 3.298 \\
\hline IAC Milênio & $13 \mathrm{a}$ & $3,9 \mathrm{~b}$ & 30,6 a & 3.802 \\
\hline IPR 139 & $12 \mathrm{a}$ & $4,1 b$ & 29,6 a & 3.452 \\
\hline IPR Andorinha & $11 \mathrm{a}$ & $3,9 \mathrm{~b}$ & $26,8 \mathrm{~b}$ & 3.071 \\
\hline TAA Bola Cheia & $10 \mathrm{~b}$ & $4,1 b$ & $30,8 \mathrm{a}$ & 3.225 \\
\hline TAA Dama & $10 \mathrm{~b}$ & $4,5 \mathrm{a}$ & $30,8 \mathrm{a}$ & 3.555 \\
\hline TAA Gol & $9 \mathrm{~b}$ & $4,1 \mathrm{~b}$ & 27,2 b & 3.125 \\
\hline ANfc 9 & $10 \mathrm{~b}$ & $4,1 \mathrm{~b}$ & $34,5 \mathrm{a}$ & 3.504 \\
\hline Média & 11 & 4,3 & 29,2 & 3.460 \\
\hline Teste $\mathrm{F}$ & $2,78^{* *}$ & $2,91^{* *}$ & $5,63 * *$ & $1,17^{\mathrm{ns}}$ \\
\hline CV (\%) & 17,60 & 7,61 & 6,73 & 13,42 \\
\hline
\end{tabular}


Foram obtidos dois grupos de cultivares para o atributo número de grãos por vagem, sendo que a cultivar Pérola, BRSMG Madrepérola, BRS Notável, IAC Alvorada e TAA Dama obtiveram os maiores valores, comparativamente as demais (Tabela 1). Esta é uma característica que sofre menos influência das condições ambientais (ANDRADE et al., 1998), sendo mais determinada por fatores genéticos.

Considerando o atributo massa de 100 grãos, o grupo com maiores valores conteve as cultivares Pérola, IAC Alvorada, IAC Milênio, IPR 139, TAA Bola Cheia, TAA Dama e ANfc 9 (Tabela 1). Deve-se ressaltar que a massa de 100 grãos das cultivares variou de 25,9 a 34,5 g, obtidas pela IAC Imperador e ANfC 9, respectivamente. O tamanho dos grãos varia em função da cultivar, sendo um atributo muito influenciado pelo ambiente e de grande importância para o mercado consumidor (CARBONELL et al., 2010; PERINA et al., 2010). Segundo Pereira et al. (2012) a massa de 100 grãos para o tipo carioca preferida pelo consumidor deve ser acima de 25 g. Assim, pode-se inferir que todas as cultivares estudadas apresentaram desempenho satisfatório quanto a esse atributo.

As cultivares de feijoeiro não diferiram entre si para a produtividade de grãos (Tabela 1 ). A média geral obtida no experimento foi de 3.460 $\mathrm{kg} \mathrm{ha}^{-1}$, sendo superior aos valores verificados na safra de inverno irrigado no Estado de São Paulo de $2.692 \mathrm{~kg} \mathrm{ha}^{-1}$ (IEA, 2018), e superior às produtividades médias da terceira safra de todos os estados brasileiros (CONAB, 2019), evidenciando $\mathrm{o}$ alto potencial produtivo das cultivares estudadas, independentemente do ciclo.

As cultivares IAC Imperador, IPR Andorinha e TAA Gol obtiveram produtividades acima de $3.000 \mathrm{~kg} \mathrm{ha}^{-1}$. Essas cultivares de feijoeiro apresentam ciclo precoce, ou seja, número médio de dias entre a emergência das plântulas até a maturação fisiológica das vagens menor que 75 dias. Segundo Lemos et al. (2015), no Brasil, a maioria das cultivares são de ciclo normal, porém a precocidade é um atributo cada vez mais procurado pelo produtor, pois permite a melhor adequação da lavoura dentro de um sistema de rotação de culturas e de consorciação, economia de água e da matriz energética em sistemas irrigados, colocação da cultura dentro de um período do ano mais favorável em termos climáticos ao desenvolvimento das plantas e retorno do capital investido mais rápido.

A cultivar IAC Alvorada apresentou desempenho superior em todos os componentes de produção (Tabela 1). A cultivar BRSMG Madrepérola obteve elevado número de grãos por vagem. A cultivar IAC Milênio apresentou maior número de vagens por planta e massa de 100 grãos. As cultivares Pérola, BRSMG Madrepérola, BRS Notável e TAA Dama apresentaram maior número de grãos por vagem. A cultivar ANfC 9, apresentou a maior massa de 100 grãos. A cultivar BRS Estilo, obteve valores para os componentes de produção e produtividade de grãos próximos da média experimental. Apesar dos diferentes desempenhos entre as cultivares para cada atributo, não se obteve diferença estatística em relação à produtividade de grãos (Tabela 1). Isso pode ser justificado pela produtividade ser resultado da combinação de seus componentes de produção fatores que são influenciados por fatores genéticos e ambientais (FAGERIA et al., 2015).

Outro fator que pode influenciar os componentes de produção e consequentemente a produtividade de grãos no feijoeiro é a ocorrência de altas temperaturas na fase reprodutiva. Temperaturas diurnas acima de 30 ${ }^{\circ} \mathrm{C}$ e noturnas superiores a $20{ }^{\circ} \mathrm{C}$ provocam abortamento de órgãos reprodutivos como flores e vagens em formação (DIDONET; VITÓRIA, 2006). Durante a fase reprodutiva observou-se temperaturas diurnas superiores a $30^{\circ} \mathrm{C}$, em duas épocas, 29 de agosto a 04 de setembro e 15 a 25 de setembro, sendo que este período coincidiu com a maturação fisiológica das vagens, e em apenas dois dias a temperatura noturna foi superior a $20^{\circ} \mathrm{C}$ durante o ciclo (Figura 1 ).

Assim, a produtividade de grãos não foi tão influenciada por essa condição climática em razão dos benefícios promovidos ao uso de irrigação e tratos culturais adequados. $\mathrm{O}$ fornecimento de água, a disponibilidade adequada de nutrientes no solo e o controle das plantas daninhas proporcionaram um ambiente adequado dentro do sistema de produção adotado, proporcionando produtividades bem acima da média de todos os estados brasileiros (CONAB, 2019). O melhoramento genético vem trabalhando na busca por cultivares tolerantes à altas temperaturas, em razão do avanço da cultura do feijoeiro para outras regiões do 
Cerrado do Brasil, como o Estado do Mato Grosso (PEREIRA et al., 2012), podendo-se citar a cultivar ANfC 9.

$\mathrm{Na}$ avaliação referente ao tamanho dos grãos das cultivares, houve diferença significativa em todas as peneiras de classificação (Tabela 2). Na média geral, a maior quantidade de grãos ficou retida na peneira 13 , com rendimento superior a 38\%, destacando-se as cultivares BRSMG Madrepérola, BRS Notável, IAC Alvorada, IAC Milênio, IPR 139, IPR Andorinha e TAA Gol. A maioria das cultivares apresentaram $\mathrm{RP} \geq 12$ acima de $70 \%$, o que representa grãos graúdos e com maior retorno financeiro, segundo Carbonell et al. (2010).

Tabela 2. Rendimento de peneira (RP) com grãos retidos nas peneiras de crivos $11,12,13$, 14 e 15 , bem como maior ou igual a 12 de cultivares de feijoeiro do grupo comercial carioca, no período de inverno ${ }^{(1)}$.

\begin{tabular}{|c|c|c|c|c|c|c|}
\hline \multirow{3}{*}{ Cultivares } & \multicolumn{6}{|c|}{ Rendimento de Peneiras - RP ${ }^{(1)}$} \\
\hline & RP 11 & RP 12 & RP 13 & RP 14 & RP 15 & $\mathrm{RP} \geq 12$ \\
\hline & \multicolumn{6}{|c|}{ 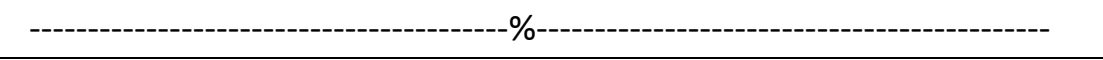 } \\
\hline Pérola & $13,0 \mathrm{~b}$ & $28,6 \mathrm{~b}$ & $34,7 \mathrm{~b}$ & $9,7 \mathrm{~b}$ & $1,0 \mathrm{~b}$ & $74,2 \mathrm{~b}$ \\
\hline BRS Estilo & $8,4 \mathrm{c}$ & $23,4 \mathrm{~b}$ & $36,9 \mathrm{~b}$ & $24,1 \mathrm{a}$ & $1,4 \mathrm{~b}$ & 85,9 a \\
\hline BRSMG Madrepérola & $6,5 \mathrm{c}$ & $19,4 \mathrm{c}$ & $56,3 \mathrm{a}$ & $12,6 \mathrm{~b}$ & $1,1 \mathrm{~b}$ & $89,5 \mathrm{a}$ \\
\hline BRS Notável & $8,6 \mathrm{c}$ & $24,9 \mathrm{~b}$ & 49,4 a & $12,0 \mathrm{~b}$ & $0,5 \mathrm{~b}$ & 86,9 a \\
\hline IAC Alvorada & $8,5 \mathrm{c}$ & $22,0 \mathrm{c}$ & 45,1 a & $18,0 \mathrm{~b}$ & $1,0 \mathrm{~b}$ & $86,2 \mathrm{a}$ \\
\hline IAC Imperador & $18,0 \mathrm{a}$ & 39,4 a & $24,0 \mathrm{~b}$ & $2,6 b$ & $0,3 \mathrm{~b}$ & $66,5 \mathrm{c}$ \\
\hline IAC Milênio & $6,4 \mathrm{c}$ & $20,3 \mathrm{c}$ & 43,6 a & 24,8 a & $1,6 \mathrm{~b}$ & 90,4 a \\
\hline IPR 139 & $11,2 b$ & $25,3 \mathrm{~b}$ & $41,7 \mathrm{a}$ & $13,8 \mathrm{~b}$ & $1,2 \mathrm{~b}$ & $82,1 \mathrm{a}$ \\
\hline IPR Andorinha & $11,1 b$ & $27,4 \mathrm{~b}$ & 47,5 a & $8,1 \mathrm{~b}$ & $1,0 \mathrm{~b}$ & $84,0 \mathrm{a}$ \\
\hline TAA Bola Cheia & $7,4 \mathrm{c}$ & $19,3 \mathrm{c}$ & $31,3 \mathrm{~b}$ & $32,5 \mathrm{a}$ & $3,2 \mathrm{~b}$ & 86,3 a \\
\hline TAA Dama & $2,8 \mathrm{c}$ & $10,5 \mathrm{c}$ & $25,3 \mathrm{~b}$ & 40,7 a & $18,7 \mathrm{a}$ & $95,3 \mathrm{a}$ \\
\hline TAA Gol & $7,6 \mathrm{~b}$ & $27,5 \mathrm{~b}$ & 47,7 a & $12,2 \mathrm{~b}$ & $1,3 \mathrm{~b}$ & 88,7 a \\
\hline ANfc 9 & $4,8 \mathrm{c}$ & $11,3 \mathrm{c}$ & $22,1 \mathrm{c}$ & 30,9 a & $24,0 \mathrm{a}$ & $88,4 \mathrm{a}$ \\
\hline Média & 8,8 & 23,1 & 38,9 & 18,7 & 4,3 & 85,0 \\
\hline Teste F & $10,66^{* *}$ & $6,41^{* *}$ & $6,98^{* *}$ & $8,66 * *$ & $14,43^{* *}$ & $11,16^{*}$ \\
\hline CV (\%) & 26,85 & 25,72 & 21,02 & 40,59 & 92,50 & 5,22 \\
\hline
\end{tabular}

A cultivar IAC Imperador obteve apenas $66,5 \%$ para o $R P \geq 12$, isso se deve a menor massa de 100 grãos como se observa na Tabela 1, bem como os maiores valores de grãos retidos nas peneiras de menor crivo, 11 e 12. A cultivar Pérola, apesar de apresentar elevada massa de 100 grãos, de $30,3 \mathrm{~g}$ (Tabela 1), foi obtido valor para o RP $\geq 12$ próximo de $70 \%$. Essa cultivar ainda é cultivada no Brasil devido sua ampla adaptabilidade e estabilidade de produção e padrão de comercialização, em razão do formato e tamanho de grãos do tipo carioca (PEREIRA et al., 2009; CARBONELL et al., 2010).

Deve-se ressaltar que as demais cultivares, com exceção da IAC Imperador, obtiveram valores estatisticamente superiores para o $\mathrm{RP} \geq 12$ em relação a cultivar Pérola, o que demonstra 0 avanço dos programas de melhoramento genético nesse atributo qualitativo. Destaca-se que as cultivares TAA Dama e IAC Milênio obtiveram valores de RP $\geq 12$ acima de $90 \%$, devido aos valores expressivos de grãos retidos nas peneiras de crivo 14 e 15, 13 e 14 respectivamente. As cultivares ANfc 9 e TAA Dama apresentaram maiores quantidades de grãos retidos na peneira 15 , sendo obtido os valores de $24 \%$ e $18 \%$, respectivamente. Essas cultivares apresentaram elevada massa de 100 grãos com valores acima de 34 e $30 \mathrm{~g}$, respectivamente (Tabela 1 ), demonstrando que possuem grande quantidade de grãos graúdos.

As cultivares de feijoeiro não apresentaram diferença quanto ao teor de proteína bruta nos grãos (Tabela 3). A média obtida foi inferior ao verificado por Farinelli e Lemos (2010b), Mingotte et al. (2013) e Pinto 
(2015). Esse atributo qualitativo pode variar em função do local de cultivo, do efeito da interação genótipos por ambiente e da variabilidade genética entre as cultivares (BURATTO et al., 2009).

Tabela 3. Teor de proteína bruta, tempo de cozimento e relação de hidratação dos grãos, de cultivares de feijoeiro do grupo comercial carioca, no período de inverno de $2015^{(1)}$.

\begin{tabular}{lccc}
\hline Cultivares & $\begin{array}{c}\text { Teor de } \\
\text { proteína }\end{array}$ & $\begin{array}{c}\text { Tempo de cozimento } \\
--- \text { (minutos)--- }\end{array}$ & $\begin{array}{c}\text { Relação } \\
\text { de hidratação }\end{array}$ \\
\hline Pérola & 18,4 & $27 \mathrm{a}$ & $2,05 \mathrm{a}$ \\
BRS Estilo & 16,7 & $22 \mathrm{~b}$ & $2,01 \mathrm{~b}$ \\
BRSMG Madrepérola & 15,8 & $26 \mathrm{a}$ & $2,02 \mathrm{~b}$ \\
BRS Notável & 18,1 & $25 \mathrm{a}$ & $2,06 \mathrm{a}$ \\
IAC Alvorada & 18,1 & $21 \mathrm{~b}$ & $2,04 \mathrm{a}$ \\
IAC Imperador & 17,0 & $27 \mathrm{a}$ & $2,02 \mathrm{~b}$ \\
IAC Milênio & 18,3 & $28 \mathrm{a}$ & $1,98 \mathrm{c}$ \\
IPR 139 & 18,0 & $32 \mathrm{a}$ & $1,97 \mathrm{c}$ \\
IPR Andorinha & 16,8 & $22 \mathrm{~b}$ & $2,02 \mathrm{~b}$ \\
TAA Bola Cheia & 16,7 & $25 \mathrm{a}$ & $2,03 \mathrm{~b}$ \\
TAA Dama & 17,5 & $29 \mathrm{a}$ & $2,04 \mathrm{a}$ \\
TAA Gol & 16,5 & $21 \mathrm{~b}$ & $1,99 \mathrm{c}$ \\
ANfc 9 & 18,8 & $25 \mathrm{a}$ & $2,02 \mathrm{~b}$ \\
\hline Média & 17,4 & 26 & 2,02 \\
Teste F & $1,56^{\text {ns }}$ & $4,70^{* *}$ & $14,25^{* *}$ \\
CV (\%) & 8,37 & 11,89 & 0,68 \\
\hline (1) & Médias seguidas de letras iguais pertencem ao mesmo grupo, pelo método Scott-Knott $\left.(\mathrm{p}<0,05) .{ }^{*}(\mathrm{p}<0,05)\right)^{* *}$ \\
(p<0,01) e ${ }^{\text {ns }}$ (não significativo) pelo teste $\mathrm{F}$, respectivamente. & &
\end{tabular}

Os resultados do tempo de cozimento e da relação de hidratação apresentaram significância entre as cultivares de feijoeiro (Tabela 3). Com relação ao tempo de cozimento, as cultivares obtiveram média de 26 minutos, variando de 21 a 32 minutos (Tabela 3). De acordo com Proctor e Watts (1987), o tempo de cozimento entre 21 a 28 minutos é classificado como sendo de resistência normal à cocção. As cultivares de feijoeiro que não se enquadraram nessa faixa foram a IPR 139 e a TAA Dama, com 32 e 29 minutos, respectivamente. No entanto, apenas a cultivar IPR 139 não ficou dentro da faixa de tempo de cozimento preconizada como aceitável por Ramalho e Abreu (2006) que é inferior a 30 minutos.

Quanto à relação de hidratação, as cultivares Pérola, BRS Notável, IAC Alvorada e TAA Dama obtiveram os maiores valores, diferindo das demais (Tabela 3). Essa diferença é justificada pelo pequeno CV obtido para este atributo. Apesar da significância, a amplitude dos valores é pequena, não tendo relevância no ponto de vista prático. A relação de hidratação variou de 1,97 a 2,06. Entretanto, esses valores estão próximos de dois $(2,0)$, ou seja, os grãos absorveram massa de água semelhante à sua massa inicial, o que evidência desempenho satisfatório quanto a esse atributo (RAMOS JUNIOR et al., 2005; FARINELLI; LEMOS, 2010b; MINGOTTE et al., 2013; PINTO, 2015).

As equações de regressão entre o tempo de hidratação e a quantidade de água absorvida pelos grãos das cultivares de feijoeiro (Tabela 4) mostraram que o período necessário para máxima hidratação variou de 11 horas e 35 minutos (BRS Estilo) a 15 horas e 36 minutos (BRSMG Madrepérola). Portanto, houve diferença de 4 horas, sendo considerado um valor elevado. As cultivares que obtiveram maiores tempos de hidratação, foram BRSMG Madrepérola e IPR 139 com valores de 15 horas e 36 minutos e 14 horas e 22 minutos, respectivamente. 
Tabela 4. Equação de regressão entre o tempo para hidratação de grãos e quantidade de água absorvida pelos grãos, tempo para máxima hidratação de grãos (TMH) de cultivares de feijoeiro do grupo comercial carioca, no período de inverno ${ }^{(1)}$.

\begin{tabular}{|c|c|c|c|}
\hline Cultivares & Equação de regressão ${ }^{(2)}$ & $\mathrm{R}^{2(3)}$ & $\mathrm{TMH}$ \\
\hline Pérola & $y=-7 E-05 x^{2}+0,1161 x+4,4738$ & 0,98 & $13: 49 a$ \\
\hline BRS Estilo & $y=-7 E-05 x^{2}+0,0974 x+15,942$ & 0,81 & $11: 35 b$ \\
\hline BRSMG Madrepérola & $y=-6 E-05 x^{2}+0,1112 x-0,9522$ & 0,99 & $15: 36 a$ \\
\hline BRS Notável & $y=-8 E-05 x^{2}+0,1203 x+8,2284$ & 0,94 & $12: 31 \mathrm{~b}$ \\
\hline IAC Alvorada & $y=-7 E-05 x^{2}+0,1107 x+4,6196$ & 0,98 & $13: 40 \mathrm{~b}$ \\
\hline IAC Imperador & $y=-7 E-05 x^{2}+0,1086 x+8,9274$ & 0,94 & $12: 30 \mathrm{~b}$ \\
\hline IAC Milênio & $y=-7 E-05 x^{2}+0,1058 x+9,1625$ & 0,93 & $12: 35 b$ \\
\hline IPR 139 & $y=-6 E-05 x^{2}+0,1035 x+3,4575$ & 0,99 & $14: 22 \mathrm{a}$ \\
\hline IPR Andorinha & $y=-7 E-05 x^{2}+0,1110 x+8,3782$ & 0,95 & $13: 13 b$ \\
\hline TAA Bola Cheia & $y=-7 E-05 x^{2}+0,1070 x+10,533$ & 0,92 & $12: 22 b$ \\
\hline TAA Dama & $y=-8 E-05 x^{2}+0,1132 x+12,135$ & 0,89 & $11: 47 b$ \\
\hline TAA Gol & $y=-7 E-05 x^{2}+0,1102 x+7,9220$ & 0,95 & $12: 42 b$ \\
\hline ANfc 9 & $y=-6 E-05 x^{2}+0,1007 x+8,2277$ & 0,95 & $13: 38 b$ \\
\hline Média & - & - & $13: 12$ \\
\hline Teste F & - & - & $4,80 * *$ \\
\hline CV (\%) & - & - & 8,68 \\
\hline
\end{tabular}

De acordo com a metodologia utilizada, descrita na Instrução Normativa no 25 de 23/05/2006 do Ministério da Agricultura, Pecuária e Abastecimento-MAPA (BRASIL, 2006), que considera como padrão o tempo de 16 horas de hidratação dos grãos em água destilada, todas as cultivares apresentaram desempenho satisfatório para obterem a completa absorção de água. No entanto, como geralmente os grãos de feijão são deixados em maceração na noite anterior ao preparo, por um período de aproximadamente 12 horas (RAMOS JUNIOR et al., 2005), observou-se comportamento satisfatório somente nas cultivares BRS Estilo e TAA Dama.

\section{Conclusões}

Todas as cultivares de feijoeiro destacaram-se quanto a produtividade de grãos, com valor médio de $3.400 \mathrm{~kg} \mathrm{ha}^{-1}$, superando as produtividades médias de todos os estados brasileiros.
As cultivares, BRS Estilo, IAC Alvorada, IPR Andorinha e TAA Gol apresentaram boa qualidade tecnológica dos grãos, destacando-se o elevado rendimento de peneiras e os menores tempos de cozimento.

As cultivares BRS Estilo e TAA Dama apresentaram tempo de hidratação ideal, enquanto as cultivares Pérola, BRSMG Madrepérola e IPR 139 demandam maior tempo para o preparo.

\section{Referências}

ALMEIDA, O.M.D.E.; MELO, H.C.D.E. Growth and Yield of the Common Bean in Response To Combined Application of Nitrogen and Paclobutrazol. Revista Caatinga, v.29, n.1, p.127132, 2016. http://dx.doi.org/10.1590/198321252016v29n115rc

AMBROSANO, E.J.; WUTKE, E.B.; BULISANI, E.A.; CANTARELLA, H. Feijão. In: RAIJ, B. van; CANTARELLA, H.; QUAGGIO, J.A.; FURLANI, A.M.C. (Ed.). Recomendação de adubação e 
calagem para o Estado de São Paulo. 2. ed. Campinas: Instituto Agronômico, 1997. p. 194195. (Boletim técnico, 100).

ANDRADE, M.J.B.; DINIZ, A.R.; CARVALHO, J.G.; LIMA, S.F. Resposta da cultura do feijoeiro à aplicação foliar de molibdênio e às adubações nitrogenadas de plantio e cobertura. Ciência e Agrotecnologia, v.22, n.4, p.499-508, 1998.

BRASIL. Ministério da Agricultura, Pecuária e Abastecimento. Registro nacional de cultivares. Disponível em: <http://www.agricultura.gov.br/>. Acesso em: 11 mar. 2019.

BRASIL. Ministério da Agricultura, Pecuária e Abastecimento. Anexo I - Requisitos mínimos para determinação do valor de cultivo e uso de feijão (Phaseolus vulgaris) para a inscrição no registro nacional de cultivares - RNC-2006. Brasília, DF, 2006.

BURATTO, J.S.; MODA-CIRINO, V.; SCHOLZ, M.B.S.; LANGAME, D.E.M.; FONSECA JÚNIOR, N.; PRETE, C.E.C. Variabilidade genética e efeito do ambiente para o teor de proteína em grãos de feijão. Acta Scientiarum. Agronomy, v.31, n.4, p.593-597, 2009. http://dx.doi.org/10.4025/actasciagron.v31i4.910

CARBONELL, S.A.M.; CHIORATO, A.F.; GONÇALVES, J.G.R.; PERINA, E.F.; CARVALHO, C.R.L. Tamanho de grão comercial em cultivares de feijoeiro. Ciência Rural, v.40, n.10, p.20672073, 2010. http://dx.doi.org/10.1590/S0103$\underline{84782010005000159}$

CONAB. Acompanhamento da safra brasileira de grãos: 2018/19, quinto levantamento. Brasília: Conab, 2019.

DIDONET, A.D.; VITÓRIA, T.B. Resposta do feijoeiro comum ao estresse térmico aplicado em diferentes estágios fenológicos. Pesquisa Agropecuária Tropical, v.36, n.3, p.199-204, 2006.

EMBRAPA. Centro Nacional de Pesquisa de Solos. Sistema brasileiro de classificação de solos. 5 . ed. Embrapa, Brasília. 356 pp. 2018.

FAGERIA, N.K.; STONE, L.F.; SANTOS, A.B. dos; CARVALHO, M. da C.S. Nutrição mineral do feijoeiro. Brasília: Embrapa, 2015.
FARINELLI, R.; LEMOS, L.B. Características agronômicas de genótipos de feijoeiro cultivados nas épocas das secas e das águas. Bragantia, v.69, n.2, p.361-366, 2010a. http://dx.doi.org/10.1590/S0006$\underline{87052010000200013}$

FARINELLI, R.; LEMOS, L.B. Qualidade nutricional e tecnológica de genótipos de feijão cultivados em diferentes safras agrícolas. Bragantia, v.69, n.3, p.759-764, 2010b. http://dx.doi.org/10.1590/S0006$\underline{87052010000300030}$

FERREIRA, D.F. Sisvar: a computer statistical analysis system. Ciência e Agrotecnologia, v.35, n.6, p.1039-1042, 2011. http://dx.doi.org/10.1590/S1413$\underline{70542011000600001}$

IEA. Previsões e estimativas das safras agrícolas do estado de São Paulo, intenção de plantio do ano agrícola 2018/19 e levantamento final ano agrícola 2017/18, setembro de 2018. Análises e Indicadores do Agronegócio, v.13, n.11, p.1-10, 2018.

JESUS, F.F.; SOUZA, R.T.G.; TEIXEIRA, G.C.S.; TEIXEIRA, I.R.; DEVILLA, I.A. Propriedades físicas de sementes de feijão em função de teores de água. Engenharia na Agricultura, v. 21 n. 1, p. 918.

2013. https://doi.org/10.13083/reveng.v21i1.39 $\underline{0}$

LEMOS, L.B.; MINGOTTE, F.L.C.; FARINELLI, R. Cultivares. In: ARF, O.; LEMOS, L.B.; SORATTO, R.P.; FERRARI, S. (Ed.). Aspectos gerais da cultura do feijão Phaseolus vulgaris L. Botucatu: FEPAF, 2015. p.181-207.

LOPES, A.S.; PAVANI, L.C.; CORÁ, J.E.; ZANINI, J.R.; MIRANDA, H.A. Manejo da irrigação (tensiometria e balanço hídrico climatológico) para a cultura do feijoeiro em sistemas de cultivo direto e convencional. Engenharia Agrícola, v.24, n.1, p.89-100, 2004. http://dx.doi.org/10.1590/S0100$\underline{69162004000100011}$

MARTINS, M.; FONSECA, L.F.; MELO, L. C.; OLIVEIRA, D.R.F.; ALVIM, K.R.T.; SANTANA, D.G. Avaliação de genótipos de feijoeiro comum do grupo comercial carioca cultivados nas épocas 
das águas e do inverno em Uberlândia, Estado de Minas Gerais. Acta Scientiarum Agronomy, v.31 n.1, p.23-28, 2009. http://dx.doi.org/10.4025/actasciagron.v31i1.660 $\underline{6}$

MELO, C.L.P.; ALVAREZ, R.C.F.; ARF, O.; CORREA, A.M.; PEREIRA, H.S.; MELO, L.C.; FARIA, L. C. BRS Notável: nova cultivar de feijoeiro comum semiprecoce do grupo carioca para Mato Grosso do Sul. Dourados: Embrapa Agropecuária Oeste, 2012. 4 p. (Comunicado técnico, 179).

MINGOTTE, F.L.C.; GUARNIERI, C.C. de; FARINELLI, R.; LEMOS, L.B. Desempenho produtivo e qualidade pós-colheita de genótipos de feijão do grupo comercial carioca cultivados na época de inverno-primavera. Bioscience Journal, v.29, p.1101-1110, 2013.

PACHECO, A.; OLIVEIRA, G.Q.; LOPES, A.S.; BARBOSA, A.S. Manejos de irrigação e nitrogênio na produção de feijoeiro sob plantio direto. Pesquisa Agropecuária Tropical, v.42, n.3, p.323330, 2012.

PEREIRA, H.S.; ALMEIDA, V.M.; MELO, L.C.; WENDLAND, A.; FARIA, L.C.; PELOSO, M.J.D.; MAGALD, M.C.S. Influência do ambiente em cultivares de feijoeiro-comum em cerrado com baixa altitude. Bragantia, v.71, n.2, p.165-172, $2012 . \quad$ http://dx.doi.org/10.1590/5000687052012005000024

PEREIRA, H.S.; MELO, L.C.; FARIA, L.C.; DEL PELOSO, M.J.; COSTA, J.G.C.; RAVA, C.A.; WENDLAND, A. Adaptabilidade e estabilidade de genótipos de feijoeiro-comum com grãos tipo carioca na Região Central do Brasil. Pesquisa Agropecuária Brasileira, v.44, n.1, p.29-37, 2009. http://dx.doi.org/10.1590/S0100-

204X2009000100005

PERINA, E.F.; CARVALHO, C.R.L.; CHIORATO, A.F.; GONÇALVES, J.G.R.; CARBONELL, S.A.M. Avaliação da estabilidade e adaptabilidade de genótipos de feijoeiro (Phaseolus vulgaris L.) baseada na análise multivariada da performance genotípica. Ciência e Agrotecnologia, v.34, n.2, p.398-406, $2010 . \quad$ http://dx.doi.org/10.1590/S1413$\underline{70542010000200018}$

PINTO, C.C. Atributos produtivos e qualitativos de grãos e fisiológicos e sanitários das sementes de cultivares de feijoeiro. 2015. 63 f. Dissertação (Mestrado em Agronomia - Produção Vegetal) Faculdade de Ciências Agrárias e Veterinárias, Universidade Estadual Paulista "Júlio de Mesquita Filho", Jaboticabal.

PIZZAN, N.R.; BULISANI, E.A.; BERTI, A.J. Feijão/Zoneamento ecológico e épocas de semeadura para o Estado de São Paulo. Campinas: CATI, 1994. p.5. (Boletim Técnico 218).

PROCTOR, J.R.; WATTS, B.M. Development of a modified Mattson bean cooker procedure based on sensory panel cookability evaluation. Canadian Institute of Food Science and Technology Journal, v.20, n.1, p.9-14, 1987. https://doi.org/10.1016/S0315-5463(87)70662-2

RAMALHO, M.A.P.; ABREU, A.F.B. Cultivares. In: VIEIRA, C.; PAULA JUNIOR, T.J. de; BORÉM, A. (Ed.). Feijão. 2.ed. Viçosa: UFV, 2006. p.415-436.

RAMOS JUNIOR, E.U.; LEMOS, L.B.; SILVA, T.R.B. Componentes da produção, produtividade de grãos e características tecnológicas de cultivares de feijão. Bragantia, v.64, n.1, p.75-82, 2005. http://dx.doi.org/10.1590/S0006$\underline{87052005000100008}$

SARRUGE, J.R., HAAG, H.P. Análises químicas de plantas. Piracicaba: Escola Superior de Agricultura Luiz de Queiroz, 1974.

SILVA, M.M.; SOUZA, H.R.T.; DAVID, A.M.S.S.; SANTOS, L.M.; SILVA, R.F.; AMARO, H.T.R. Qualidade fisiológica e armazenamento de sementes de feijão-comum produzidas no norte de Minas Gerais. Revista Agro@mbiente, v.8, n.1, 8470ragro.v8i1.1346

SCOTT, A.; KNOTT, M. A cluster-analysis method for grouping means in the analysis of variance. Biometrics, v.30, n.3, p.507-512, 1974.

TALUKDER, Z.I.; ANDERSON, E.; MIKLAS, P.N.; BLAIR, M.W.; OSORNO, J.; DILAWARI, M.; HOSSAIN, K. G. Genetic diversity and selection of genotypes to enhance $\mathrm{Zn}$ and Fe content in common bean. Canadian Journal of Plant Science, v.90, n.1, p.49-60, 2010. https://doi.org/10.4141/CJPS09096 